\title{
IMIA Award of Excellence in Medical Informatics 2010 has been given jointly to Dr. Marion Ball and Dr. Hans Peterson
}

At its 2001 General Assembly in London, the International Medical Informatics Association (IMIA) approved the establishment of a Medical Informatics Award of Excellence. Since then, this Award of Excellence has been given every three years in conjunction with IMIA's World Congress in Medical Informatics, Medinfo.

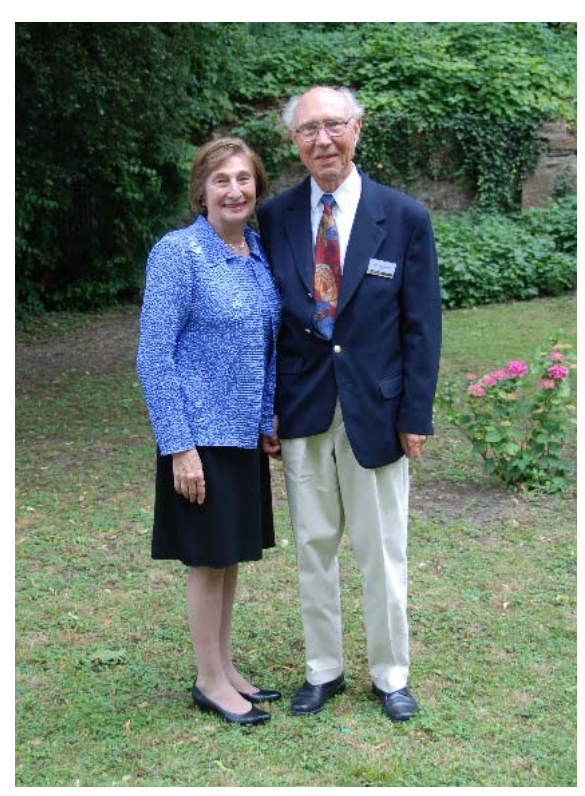

The criteria for a potential recipient of the Medical Informatics Award of Excellence are: "an individual whose personal commitment and dedication to medical informatics has made a lasting contribution to medicine and healthcare through her or his achieve- ments in research, education, development or application in the field of medical infor-matics, and in recognition that her or his contributions to the field exemplify the highest ideals of the IMIA vision and guiding principles."

The first award was given at Medinfo 2004 in San Francisco, USA, to Dr. François Grémy, France. The recipient of the second award, made at Medinfo 2007 in Brisbane, Australia, was Dr. Jan $H$. van Bemmel from The Netherlands.

In seeking nominations for the third IMIA Award of Excellence, to be presented at Medinfo 2010 in Cape Town, South Africa, the nominating committee for IMIA's highest award received several suggestions of excellent candidates. Although it was difficult to select between these outstanding persons, the nominating committee finally made a unanimous decision that the IMIA Award of Excellence in Medical Informatics 2010 should be given jointly to two persons:

\section{Dr. Marion Ball and \\ Dr. Hans Peterson from Sweden.}

from the United States of America

Without going into detail on their many merits, and without mentioning their awards and honorable positions, it should be highlighted that both recipients are among the most recognized pioneers and international leaders in medical informatics. Their contribution to setting up an international medi- cal informatics association with conferences, publications, working groups etc. and so to internationally stimulating high-quality research, education and practice, as well as international collaboration, can hardly be underestimated.

Although they have been involved in many international projects and activities, it should also be mentioned that both recipients have also significantly contributed to the progress of medical informatics - and so to medicine and health care - in their respective countries and regions, i.e. Marion Ball for the US and Hans Peterson for Sweden and more widely for Scandinavia.

Dr. Marion Ball gave a keynote lecture during Medinfo 2010. Unfortunately, due to health problems of his wife, Dr. Hans Peterson could (for he first time ever!) not attend this Medinfo congress. As a consequence, in the closing ceremony of this conference, Hans Peterson's award lecture was missing. The then IMIA President Reinhold Haux, together with IMIA Award recipient Marion Ball, both honoured Hans Peterson in their speeches.

It is my hope that a written version of the lectures of both award recipients will be elaborated and published. As with already published lectures of the two previous recipients, these manuscripts will certainly form an important part of preserving the knowledge of the development of medical informatics.

October 2010

Dr. Reinhold Haux

Past-President, International Medical Informatics Association 